INTERVENTIONAL CARDIOLOGY AND SURGERY

\title{
Intrathoracic organ transplantation in the United Kingdom 1995-99: results from the UK cardiothoracic transplant audit
}

\author{
A C Anyanwu, C A Rogers, A J Murday, and the Steering Group
}

Heart 2002;87:449-454

See end of article for authors' affiliations

......................

Correspondence to: Andrew Murday, Director of Intrathoracic

Transplantation, Scottish

Cardiopulmonary

Transplant Unit, Glasgow

Royal Infirmary, Alexandra

Parade, Glasgow

G31 2ER, UK;

andrew.murday@

btinternet.com

Accepted

25 January 2002 plantation in the United Objective: To describe the current practice and outcomes of intrathoracic transplantation in the United
Kingdom.

Design: Prospective observational cohort study.

Setting: Multicentre study involving all nine UK intrathoracic transplant units.

Patients: 2588 patients added to the national waiting list between April 1995 and March 1999 and

1737 patients who underwent heart, lung, or heart-lung transplantation in the same period.

Main outcome measures: Waiting list mortality and post-transplant graft survival.

Results: There was a slight fall in transplant activity over the four years. Within six months of listing, $52.5 \%$ of patients on the heart transplant list had been transplanted and $11.0 \%$ had died, compared with $31.3 \%$ and $15.2 \%$ for lung, and $23.4 \%$ and $20.4 \%$ for heart-lung. The median time to transplant in days (95\% confidence interval) was 133 (115 to 149) for heart, 386 (328 to 496) for lung, and 471 (377 to 577) for heart-lung. After three years, the waiting list mortality was $16.9 \% 16.1 \%$ to $46.8 \%)$ for heart, $33.1 \%(9.0 \%$ to $100 \%)$ for lung, and $36.5 \%(10.5 \%$ to $100 \%)$ for heart-lung. The three year graft survival after transplantation was $74.2 \%(71.2 \%$ to $77.0 \%)$ for heart, $53.8 \%(48.2 \%$ to $59.2 \%)$ for lung, and $57.2 \%(49.0 \%$ to $64.6 \%)$ for heart-lung.

Conclusions: This validated database defines the current state of thoracic transplantation in the United Kingdom and is a useful source of data for workers involved in the field. Thoracic transplantation is still limited by donor scarcity and high mortality. Overoptimistic reports may reflect publication bias and are not supported by data from this national cohort.
$\mathrm{H}$ eart, lung, and heart-lung transplantation are established treatments for end stage cardiopulmonary disease. The UK cardiothoracic transplant audit is a national study, funded by the Department of Health, to examine various aspects of thoracic transplantation in the United Kingdom. The cardiothoracic transplant audit was established to provide a valid tool for auditing outcomes after thoracic transplantation. In this paper we describe the study methods and present descriptive and early outcome data on transplants performed in the United Kingdom between 1995 and 1999.

\section{METHODS}

\section{The UK cardiothoracic transplant audit}

The UK cardiothoracic transplant audit was established to describe the practice of intrathoracic transplantation in the United Kingdom, provide clinical audit, and, by examining outcomes and process, to improve cardiopulmonary transplant provision. The audit is overseen by a steering group, which comprises the director of each transplant unit, the director of the Clinical Effectiveness Unit at the Royal College of Surgeons, and a Department of Health representative. This paper concerns the description of current practice of intrathoracic transplantation in the United Kingdom only. Other analyses from the audit are presented elsewhere.

\section{Study design}

The UK cardiothoracic transplant audit is an ongoing multicentre prospective cohort study involving all nine United Kingdom thoracic transplant centres. All patients listed for transplantation and all transplants performed in the United Kingdom since April 1995 are recruited. There are no exclusions. Eligible patients are tracked through the national waiting list and transplant database at the United Kingdom Transplant (UKT). There are four data collection points: time of placement on the waiting list, time of transplant, three months post-transplant, and at the annual anniversary of the transplant until death. Data are collected by locally assigned staff in each of the transplant units and submitted to UKT, which processes the data on behalf of the audit. Rigorous data validation is undertaken and consists of three components: data validation at entry, restricting data to valid responses only; computer screening of the database for suspect and invalid data; and periodic visits to centres for direct comparison between submitted data and patient medical records.

\section{End points}

The primary end points for this study are mortality and graft survival. Graft survival (defined as the time to retransplantation or death) and patient survival are virtually the same for United Kingdom thoracic transplants because of a low retransplant rate (less than $2 \%$ of all transplants). Other study end points include rejection, infection, early post-surgery complications, serum creatinine, and New York Heart Association (NYHA) functional class.

\section{Analysis cohorts}

Between April 1995 and March 1999, 2648 patients were added to the national waiting list for intrathoracic organ transplantation. At the time of this analysis, audit registration data had been returned on 2588 (97.7\%) - these patients form the cohort for analyses based on the waiting list and include 1521 heart, 710 lung, and 357 heart-lung listings. For transplant data analysis, transplants performed between April 1995 and March 1999 are considered. Data were available on $99 \%$ of transplants performed within this period (1737 of 

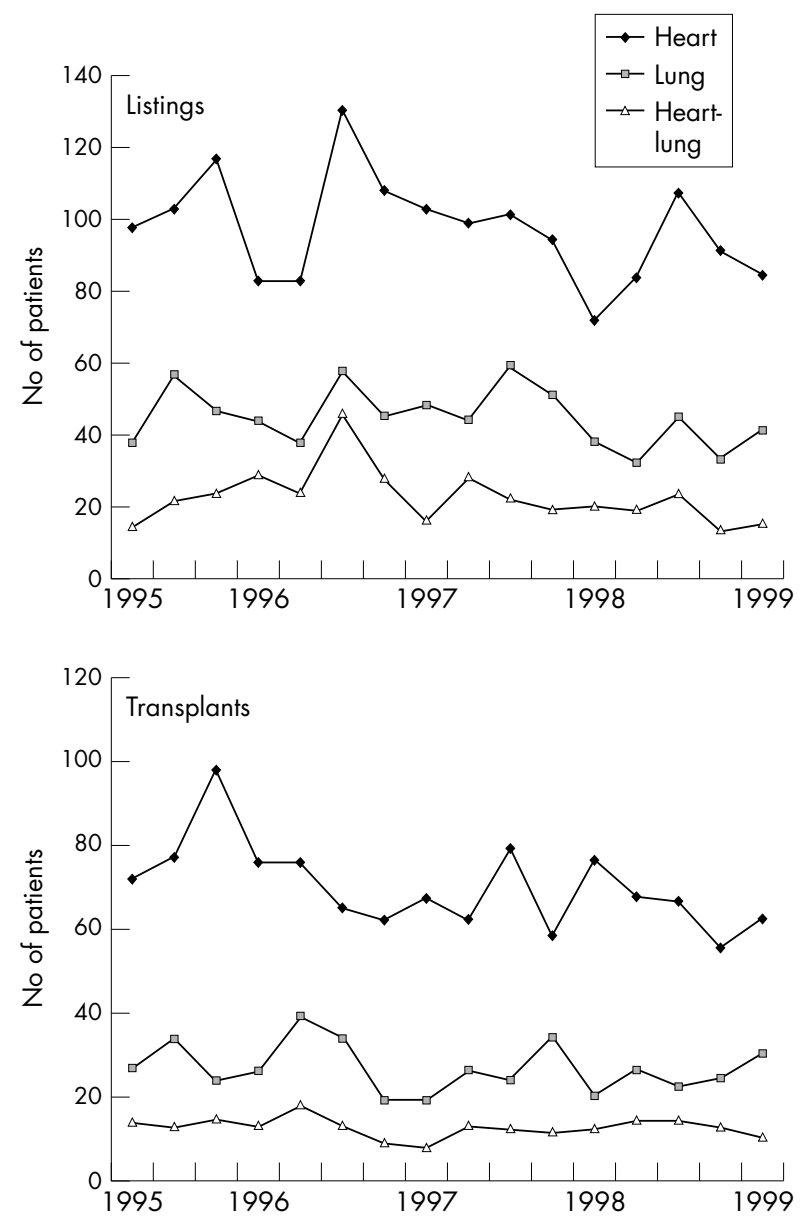

Figure 1 Number of patients added to waiting list and the number of transplants per quarter year.

1750); these transplants-1114 heart, 426 lung, and 197 heart-lung-form the cohort for transplant analysis. For outcome analysis of this cohort, events up to July 2000 are considered. One year and two year follow up data were available for most transplants (97\% and 95\%; $95 \%$ and 95\%; and $97 \%$ and $93 \%$ of eligible heart, lung, and heart-lung grafts for one year and two year follow up, respectively). No attempts were made to direct or standardise practice in the participating centres; the study therefore represents transplantation as currently practised by the various transplant centres in the United Kingdom.

Preassessment protocols and practice vary in different centres, and some patients or centres have unique clinical circumstances that preclude collection of data on all variables for all patients. For example, critically ill patients undergoing emergency transplantation will not have a full work up. Some patients therefore do not have measured responses on all variables. Where variables were coded as "not measured" or "unknown," they were excluded from analysis. Because of missing data, the denominators for various analyses differ from the full samples.

\section{Statistical analysis}

The Statistical Analysis System (SAS) version 6.12 (SAS Institute, Cary, North Carolina, USA) and Stata version 6 (Stata Corporation, College Station, Texas, USA) were used for all analyses. The Kaplan-Meier method was used for survival analysis. Crude cumulative incidence rates for waiting list outcomes were calculated in the presence of competing risks. ${ }^{1}$
Table 1 Combined heart, lung, and heart-lung transplant activity in contributing centres (see appendix for full centre names)

\begin{tabular}{lll}
\hline Centre & $\begin{array}{l}\text { Listings per month } \\
\text { (mean) }\end{array}$ & $\begin{array}{l}\text { Transplants per month } \\
\text { (mean) }\end{array}$ \\
\hline Birmingham & 4.5 & 2.9 \\
Glasgow* & 3.6 & 2.6 \\
Great Ormond Street† & 2.1 & 1.4 \\
Harefield $\neq$ & 14.3 & 9.1 \\
Manchester & 5.5 & 3.1 \\
Newcastle & 8.8 & 5.6 \\
Papworth & 8.8 & 7.0 \\
Sheffield & 3.1 & 1.8 \\
St George's Hospital & 4.3 & 3.0 \\
All centres & 55.2 & 36.5 \\
\hline *Hearts only. & \\
†Paediatrics only. & \\
$\ddagger$ Adult and paediatric. & \\
\hline
\end{tabular}

RESULTS

Activity

Figure 1 shows the trend in transplant activity over the four year period. On average, 32 heart, 15 lung, and eight heart-lung patients were added to the waiting list every month. In contrast, the average numbers of heart, lung, and heart-lung transplants per month were 23, 9, and 4, respectively. There was a fall in the average number of heart transplants per month from 27 in 1995 to 22 in 1998. Numbers of lung and heart-lung transplants were relatively constant over the period. Level of activity (and hence the contribution of each centre to this analysis) varied among the nine transplant units (table 1 ).

\section{Indications for transplant and patient characteristics}

The predominant reasons for requiring a heart transplant were dilated cardiomyopathy $(\mathrm{n}=679 ; 44.7 \%)$, ischaemic heart disease $(\mathrm{n}=578 ; 38.1 \%)$, and congenital heart disease $(\mathrm{n}=94 ; 6.2 \%)$. Idiopathic pulmonary fibrosis $(\mathrm{n}=201$; $28.6 \%)$, emphysema ( $\mathrm{n}=185 ; 26.3 \%)$, and cystic fibrosis ( $\mathrm{n}=122 ; 17.3 \%$ ) were the principal reasons for listing for lung transplantation. Cystic fibrosis $(\mathrm{n}=168 ; 47.1 \%)$, primary pulmonary hypertension $(\mathrm{n}=67 ; 18.8 \%)$, and congenital heart disease $(n=53 ; 14.9 \%)$ were the most common reasons for listing for a heart-lung transplant. Heart-lung transplantation was the preferred treatment for these diagnoses, as $58 \%$ of the patients with cystic fibrosis and $87 \%$ of those with primary pulmonary hypertension who were placed on the national waiting list were listed for a heart-lung transplant. Retransplantation was an infrequent reason for listing for heart transplantation ( $\mathrm{n}=14 ; 0.9 \%)$, but was more common for lung $(\mathrm{n}=26 ; 3.7 \%)$ and heart-lung transplantation $(\mathrm{n}=8 ; 2.2 \%)$.

Table 2 shows characteristics of patients placed on the waiting lists. Centre variations existed; for example, the frequency of listing of critically ill patients (those receiving inotropes, intra-aortic balloon counterpulsation, or ventricular assist devices for circulatory support) varied from $1 \%$ to $21 \%$. The median ages at listing were 50 years for heart transplant, 49 years for lung transplant, and 27 years for heart-lung transplant. The age distribution of heart patients was negatively skewed: although the interquartile range was between 41 and 56 years and the 90th centile was 59 years, the 10th centile was 17 years because of a substantial paediatric contribution- $5 \%$ of patients added to the heart waiting list were infants or children below eight years of age. The interquartile range of the lung waiting list was similar to that of heart patients (36 to 54 years). The distribution was notably different, however: the age was bimodal with a small peak at 27 years reflecting the cystic fibrosis population and a larger 
Table 2 Characteristics of the patients on the waiting list

\begin{tabular}{|c|c|c|c|c|c|c|}
\hline \multirow[b]{2}{*}{ Characteristic } & \multicolumn{2}{|l|}{ Heart } & \multicolumn{2}{|l|}{ Lung } & \multicolumn{2}{|c|}{ Heart-lung } \\
\hline & $\mathrm{n}$ & $\%$ & $\mathrm{n}$ & $\%$ & $\mathrm{n}$ & $\%$ \\
\hline Sex: male & 1239 & 81 & 382 & 54 & 160 & 45 \\
\hline Ethnicity: white & 1402 & 92 & 662 & 93 & 332 & 93 \\
\hline CMV antibody positive & 621 & 41 & 277 & 39 & 213 & 60 \\
\hline Previous sternotomy & 532 & 35 & 17 & 2 & 37 & 10 \\
\hline AICD & 59 & 4 & - & - & - & - \\
\hline Hypertension & 306 & 20 & 27 & 4 & 14 & 4 \\
\hline Peripheral vascular disease & 29 & 2 & 3 & $<1$ & 1 & $<1$ \\
\hline Cerebrovascular disease & 82 & 5 & 4 & 1 & 4 & 1 \\
\hline Diabetic & 119 & 8 & 56 & 8 & 68 & 19 \\
\hline Past malignancy & 31 & 2 & 8 & 1 & 1 & $<1$ \\
\hline Smoker (within 6 months of listing) & 157 & 10 & 33 & 5 & 7 & 2 \\
\hline Home oxygen & 45 & 3 & 544 & 77 & 209 & 59 \\
\hline $\begin{array}{l}\text { Inotropes, mechanical circulatory or } \\
\text { ventilatory support }\end{array}$ & 221 & 15 & 13 & 2 & 22 & 6 \\
\hline NYHA: class IV & $366 / 1414$ & 26 & $162 / 651$ & 24 & $79 / 325$ & 24 \\
\hline
\end{tabular}

peak at 50 years reflecting the emphysema population. Paediatrics was a minor component of the lung waiting list $(2 \%$ below 16 years). Those listed for heart-lung transplantation were younger than for lung transplantation (heart lung: interquartile range 19 to 39 years, $17 \%$ below 16 years). The oldest patients placed on the waiting list were 70 years (heart), 66 years (lung), and 57 years (heart-lung).

\section{Waiting list outcome}

After being placed on the waiting list, patients face one of three competing outcomes: transplantation, death on the waiting list, or removal from the waiting list. The probability of receiving a transplant or dying on the waiting list varies with the length of time on the list. Few patients $(3 \%)$ were removed from the waiting list within a year of listing. The likelihood of receiving a transplant was greatest for those awaiting a heart transplant.

Within six months of listing, 52.5\% (95\% confidence interval (CI), $31.8 \%$ to $86.7 \%$ ) of those on the heart list had been transplanted, compared with $31.3 \%$ ( $10.4 \%$ to $93.8 \%)$ for lungt, and $23.4 \%$ (7.0\% to $77.9 \%)$ for heart-lung; while $11.0 \%$ $(4.5 \%$ to $27.1 \%)$ on the heart list had died on the waiting list, compared with $15.1 \%$ (4.2\% to $53.6 \%$ ) for lung, and $20.4 \%$ (6.3\% to $65.3 \%)$ for heart-lung. For patients who did receive a transplant, the median time from listing to transplantation in days was 133 ( 115 to 149) for heart, 386 (328 to 496) for lung, and 471 ( 377 to 577 ) heart-lung. Figure 2 shows the cumulative mortality rate for patients placed on the waiting list. Using the competing risks method, after three years the waiting list mortality was $16.9 \%(6.1 \%$ to $46.8 \%)$ for heart transplants, $33.1 \%(9.0 \%$ to $100 \%)$ for lung transplants, and $36.5 \%$ (10.5\% to $100 \%$ ) for heart-lung transplants. Using the Kaplan-Meier method, with patients censored if they were transplanted or removed from the waiting list, the waiting list survival after three years was $57.9 \%$ (51.6\% to $63.7 \%$ ) for heart transplant patients, $38.8 \%$ (32.2\% to $45.3 \%$ ) for lung transplant patients, and $42.0 \%(33.4 \%$ to $50.3 \%)$ for heart-lung transplant patients.

\section{Donor characteristics}

Male donors provided 59\% of transplanted organs. This proportion differed among the three transplant groups: $62 \%$ of heart and 59\% of lung grafts were from male donors, compared with $43 \%$ in the heart-lung group. The median donor age (interquartile range) for the three transplant groups was 31 ( 21 to 42 ) years for heart, 36 (25 to 45) years for lung, and 27 ( 17 to 38 ) years for heart-lung . The oldest donors were 60 years, 65 years, and 61 years for heart, lung, and heart-lung, respectively. Ninety nine transplants were per- formed with organs from live donors: 91 "domino" heart and eight lobar lung transplants.

\section{Status at transplant}

The sex and age distributions of transplanted patients were similar to those of the waiting list cohort. The ages of the oldest patients transplanted in this cohort were 71 years (heart), 67 years (lung), and 57 years (heart-lung). The underlying diseases in heart and heart-lung recipients were similar to the waiting list cohort. The lung group differed slightly, with a greater proportion of patients having emphysema (35\% of those transplanted, compared with $26 \%$ on the waiting list). Not all patients received the organs for which they were listed. Some $18 \%$ of patients transplanted from the heart-lung waiting list received lung grafts. A smaller proportion (2\%) transplanted from the lung list received heart-lung grafts.

\section{Outcome after transplantation}

Graft survival up to three years post-transplantation is shown in fig 3. The one year graft survival was $80 \%$ (95\% CI, $77 \%$ to $82 \%$ ) for heart, $68 \%$ (63\% to $73 \%$ ) for lung, and $70 \%$ (62\% to $76 \%$ ) for heart-lung. The failure rate for all transplants was highest in the first post-transplant month. Causes of early graft loss are shown in table 3. For all organs, the risk of graft failure was greatest in the first week after transplantation (probability of failure per day (hazard function) $=0.01$ ). For heart transplants the risk fell after the second week; patients who survive the second week had a much lower daily probability of death $(0.0012$, falling to 0.0002 after three

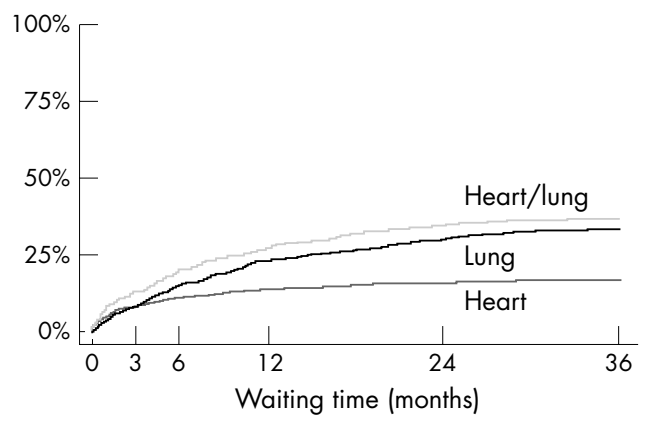

Number at risk (\% mortality):

$\begin{array}{llll}1400(0) & 291(14) & 112(16) & 44(17) \text { Heart } \\ 667(0) & 219(33) & 89(30) & 31(33) \text { Lung } \\ 338(0) & 125(27) & 44(35) & 19(36) \text { Heart/lung }\end{array}$

Figure 2 Deaths on the waiting list. 


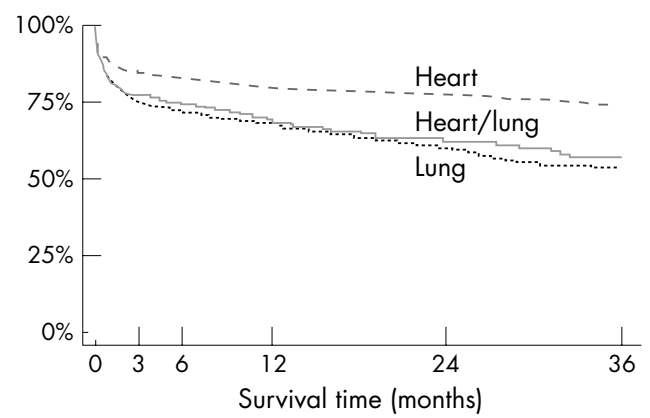

Number at risk (\% survival):

$\begin{array}{llcc}1114(100) & 770(80) & 550(78) & 318(74) \text { Heart } \\ 426(100) & 245(68) & 150(60) & 83(54) \text { Lung } \\ 197(100) & 120(70) & 75(62) & 48(57) \text { Heart/lung }\end{array}$

Figure 3 Post-transplant graft survival (event death or retransplantation).

months). The picture was different in the heart-lung and lung group - the hazard function remained high for the first three months (0.003/day at one month), accounting for separation of the lung and heart-lung from the heart survival curves after the second week (fig 3). After three months, the hazard rate fell for all grafts; having survived to three months the probability of failure fell to 0.0003 for hearts and 0.0005 for lungs and heart-lungs.

Heart transplant patients had better functional status as determined by the NYHA class, with $84 \%$ in NYHA class I at their 12 and 24 month assessment. In comparison, $62 \%$ of lung recipients and $67 \%$ of heart-lung recipients were in class I at 12 months, while $62 \%$ and $69 \%$, respectively, were in class I at 24 months. Lung and heart-lung transplant recipients therefore had worse outcomes than heart recipients in terms of both quantity and quality of survival.

\section{DISCUSSION}

The UK cardiothoracic transplant audit is one of a few multicentre collaborative studies evaluating thoracic transplantation. This study represents an almost complete recruitment of transplants performed in the one country over a four year period. Data have been subjected to extensive validation.

While much data have been published on the practice and outcome of intrathoracic transplantation, most of the published reports are derived from experience in single centres. Publication bias, selection bias, and centre variations may limit generalisation from these studies. Some multicentre studies have also been undertaken but these have either been voluntary registries, ${ }^{2-4}$ which are largely unvalidated, or collaborative studies recruiting patients from selected centres. ${ }^{5}$ The UK cardiothoracic transplant audit is unique in representing a complete non-selective validated national experience.

\section{Patient characteristics}

The indications for cardiac transplantation in the United Kingdom are similar to those recorded by the International Society for Heart and Lung Transplantation (ISHLT) registry, ${ }^{2}$ with the notable exception that listing for retransplantation is less common in the United Kingdom (less than 1\%, compared with $2.3 \%$ in the international registry). This may reflect concerns about the equitable distribution of organs and the poor results of retransplantation. ${ }^{6}$ The only other prominent difference in indications for transplant is the use of heart-lung transplantation for primary pulmonary disease. In the USA, heart-lung transplantation is rarely performed for primary pulmonary disease, whereas $45 \%$ of heart-lung recipients in the United Kingdom had cystic fibrosis. The clinical characteristics of the cardiac group (table 2) mirror that reported by the cardiologists' transplant research database, a multicentre study from North America. ${ }^{5}$

Compared with North America, where $60 \%$ of donor deaths result from trauma (UNOS activity report, www.unos.org), trauma is a less common cause of donor death in the United Kingdom (35\% of our donors died from trauma). The higher proportion of trauma deaths in the USA is largely a reflection of a higher incidence of penetrating trauma, as gun shot injuries are responsible for $20 \%$ of American donors, ${ }^{5}$ compared with less than $1 \%$ of United Kingdom donors.

\section{Waiting list outcome}

With transplantation, patients who are listed for heart transplantation in the United Kingdom have a favourable chance of either receiving a transplant or remaining alive up to three years after listing, with only $17 \%$ actually dying on the waiting list in this period (the remainder were transplanted, removed from list, or still waiting). In comparison, one third of patients waiting for lung or heart-lung transplantation had died without transplantation within three years of listing. More sophisticated analysis is required to determine which patients are more likely to die on the waiting list and which patients will derive the greatest benefit from transplantation. A study from Germany has recently suggested that heart transplantation may not carry any survival benefit, particularly in patients at low or moderate risk of death on the waiting list; the authors of that paper suggested that use of heart transplantation should be restricted to those at high risk of death on the waiting list. ${ }^{7}$ That study was, however, limited by a short duration of follow up and a low post-transplant survival. ${ }^{8}$ Consideration should be given not only to the risk of dying on the waiting list, but also to the probability of surviving the transplant operation, ${ }^{9}$ as some patients at high risk of death on the waiting list may also be at high risk of death after transplantation, thereby reducing the survival benefit. Listing of patients with relatively mild disease and those with reasonable prognosis, however, increases the demand-supply mismatch ${ }^{10}$ and should be discouraged.

The actuarial waiting list survival serves a useful proxy for what the survival would be for end stage organ failure if there

Table 3 Causes of early graft failure: cause of death for patients who died in the first 30 post-transplant days

\begin{tabular}{llll}
\hline Cause of failure & Heart & Lung & Heart-lung \\
\hline Procedure related & $7 / 129(5 \%)$ & $4 / 72(6 \%)$ & $3 / 36(8 \%)$ \\
Early graft dysfunction & $64 / 129(50 \%)$ & $19 / 72(26 \%)$ & $9 / 36(25 \%)$ \\
Infection & $10 / 129(8 \%)$ & $17 / 72(23 \%)$ & $8 / 36(22 \%)$ \\
Acute rejection & $11 / 129(9 \%)$ & $9 / 72(13 \%)$ & $4 / 36(11 \%)$ \\
Cardiac failure including & $14 / 129(11 \%)$ & $8 / 72(11 \%)$ & $2 / 36(6 \%)$ \\
pulmonary hypertension & $3 / 129(2 \%)$ & $2 / 72(3 \%)$ & $2 / 36(6 \%)$ \\
Neurological & $5 / 129(4 \%)$ & $1 / 72(1 \%)$ & $0 / 72(0)$ \\
Gastrointestinal & $15 / 129(12 \%)$ & $12 / 72(17 \%)$ & $5 / 36(14 \%)$ \\
Other & & & \\
\hline
\end{tabular}


were no transplantation. ${ }^{11-13}$ Our data suggest that mortality risk for patients placed on the waiting list is not as bad as generally perceived. Actuarial waiting list survival in our cohort is similar to that in North America ${ }^{11}$ and the Netherlands $^{12}$ (two year actuarial survival, 55\% for cystic fibrosis or interstitial pulmonary fibrosis in the USA and 58\% for all lung waiting list patients in the Netherlands). There are suggestions that advances in medical management have improved the survival without transplantation, ${ }^{14}$ and some patients currently placed on transplant waiting lists may actually have a reasonable (mortality-free) prognosis without transplantation.

\section{Graft survival}

The observed one year graft survival in our present study was at variance with suggestions that patients should now expect a one year survival of $90 \%$ for heart transplantation and $80 \%$ for lung and heart-lung transplantation. ${ }^{10}{ }^{15}$ Indeed several non-UK centres have reported one year survival figures approaching or exceeding $90 \%$ for heart transplantation ${ }^{16-20}$ and also for lung transplantation. ${ }^{12}$ The international registry, ${ }^{2}$ however, reports the one year survival for heart grafts done since 1991 as $80 \%$ and for lung grafts done since 1994 as 70\%, figures similar to those obtained in this study. An audit of a complete national cohort in Germany has recently reported a one year survival of $71 \%$ after heart transplantation. ${ }^{7}$ The most likely explanation for the difference between validated national databases and published reports is publication bias, as those centres with below average results are unlikely to publish their results. Observational studies are particularly prone to publication bias, ${ }^{21}$ and as transplantation outcome studies are largely observational, published transplant data will be especially prone to such bias.

\section{Conclusions}

The optimistic outlook at the beginning of the $1990 \mathrm{~s}^{22-25}$ and the improved outcomes reported by several centres are not reflected by results in this validated United Kingdom cohort. The problems of high mortality after transplantation and donor scarcity remain. There continues to be a disparity between the numbers of patients listed and the available donors; indeed the heart donor rates have fallen in the United Kingdom over the four year study period. Almost half the patients listed for lung transplantation will not receive a transplant, and at least a quarter will die within two years of listing, while still waiting for a donor. International registry data also suggest that there has been no significant change in survival outcome of heart transplantation since 1986 and for lung transplantation since $1991 .{ }^{2}$ Continued efforts to expand the donor pool, minimise morbidity and mortality after transplantation, and identify patients who do benefit from transplantation therefore remain crucial. The predominance of deaths in the immediate postoperative period-largely related to early graft dysfunction, infection, and rejectionpoint to the need for continued research into optimal preservation, antirejection, and infection prophylaxis strategies.

In the absence of national data, health policy and expectations are based on expert opinion, output from research studies, and publications from selected local and international centres. These may not, however, reflect the experiences in non-research settings. National audits are therefore helpful in defining the practice and outcome of interventions and establishing the degree to which research findings and results from pioneer and expert units are replicable in routine practice. We suggest that methods similar to those used in this study should be used to study other diseases and interventions where accurate and generalisable descriptions of practice are required.

\section{ACKNOWLEDGEMENTS}

We thank the centre data coordinators, Sharon Beer, Yvonne Davenport, Jane Reader, Andrea Husain, Ian Martin, Lindsay Reynolds, Sheilagh Vidler, Bruce Whithead, and Neil Wrightson, for providing us with data. Data collection and processing was done in conjunction with the United Kingdom Transplant. This work was commissioned and funded by the Department of Health. The views expressed are those of the authors and not necessarily of the Department of Health.

\section{APPENDIX}

\section{Members of Steering Group and participating centres}

Mr Robert S Bonser (Queen Elizabeth Hospital, Birmingham)

Professor John Dark (Freeman Hospital, Newcastle)

Mr Abdul K Deiraniya (Wythenshawe Hospital, Manchester)

Professor Marc R de Leval (Great Ormond Street Hospital for Sick Children, London)

Mr Timothy J Locke (Northern General Hospital, Sheffield)

Mr Andrew J Murday (St George's Hospital, London)

Mr John Wallwork (Papworth Hospital, Cambridge)

Professor David J Wheatley (Glasgow Royal Infirmary, Glasgow)

Professor Sir Magdi H Yacoub (Harefield Hospital, Middlesex)

Dr Peter Doyle (Department of Health)

Dr Barnaby Reeves (Director, Clinical Effectiveness Unit, Royal College of Surgeons of England)

Authors' affiliations

A C Anyanwu, C A Rogers, A J Murday, The UK Cardiothoracic Transplant Audit, Clinical Effectiveness Unit, The Royal College of Surgeons of England, London, UK

\section{REFERENCES}

1 Marubini E, Valsecchi MG. Analysing survival data from clinical trials and observational studies. Chichester: J Wiley and Sons, 1995.

2 Hosenpud JD, Bennett LE, Keck BM, et al. The registry of the International Society for Heart and Lung Transplantation: seventeenth official report - 2000. J Heart Lung Transplant 2000;19:909-31.

3 Opelz G. Results of cardiac transplantation and factors influencing survival based on the collaborative heart transplant study. In: Cooper DK, Miller LW, Patterson GA, eds. The transplantation and replacement of thoracic organs. Dordrecht: Kluwer, 1996:417-27.

4 Pohl MS, Cooper JD. Results of lung transplantation and factors influencing survival based on the St Louis lung transplant registry. In: Cooper DK, Miller LW, Patterson GA eds. The transplantation and replacement of thoracic organs. Dordrecht: Kluwer, 1996:595-8.

5 Bourge RC, Naftel DC, Costanzo Nordin MR, et al. Pretransplantation risk factors for death after heart transplantation: a multi-institutional study. The Transplant Cardiologists Research Database Group. J Heart Lung Transplant 1993:12:549-62.

6 Hosenpud JD, Novick R, Bennett LE, et al. The Registry of the International Society for Heart and Lung Transplantation: thirteenth official report - 1996. J Heart Lung Transplant 1996; 15:655-74.

7 Deng MC, De Meester JM, Smits JA, et al. Effect of receiving a heart transplant: analysis of a national cohort entered on to a waiting list, stratified by heart failure severity. BN 2000;321:540-5

8 Treasure T, Murday A. Commentary: time for a controlled trial? BMW 1999:321:545

9 Anyanwu AC, Rogers CA, Murday AJ. A simple approach to risk stratification in adult heart transplantation. Eur J Cardiothorac Surg $1999 ; 16: 424-8$

10 Daly RC. Lung transplantation: where are we today? Mayo Clin Proc 1997:72:77-8.

11 Hosenpud JD, Bennett LE, Keck BM, et al. Effect of diagnosis on survival benefit of lung transplantation for end-stage lung disease. Lancet 1997;351:24-7.

12 Geertsma A, TenVergert E, Bonsel GJ, et al. Does lung transplantation prolong life? A comparison of survival with and without traansplantation. $J$ Heart Lung Transplant 1998;17:511-16.

13 Michel BC, Van Hout BA, Bonsel GJ. Assessing the benefits of transplant services. Baillieres Clin Gastroenterol 1994;8:411-23.

14 Stevenson LW. Selection and management of candidates for heart transplantation. Curr Opin Cardiol 1996;11:166-73.

15 Olivari MT. Cardiac transplantation: current indications, short- and long-term results, economic implications, and future developments. J Card Fail 1996;2:141-52.

16 Reichart BA, Reichenspurner HC, Odell JA, et al. Heart transplantation at Groote Schuur Hospital, Cape Town. Twenty years' experience. S Afr Med J 1987;72:737-9. 
17 Primo G, Le Clerc JL, Antoine M, et al. A survey of nine years heart transplantation at Erasme Hospital, University of Brussels. Acta Cardiol $1991 ; 46: 555-65$.

18 Stewart RW. Cardiac transplantation at the Cleveland Clinic Foundation - the first 10 years. Clin Transpl 1994:8:127-31.

19 Livi U, Caforio AL, Tursi V, et al. Donor age greater than 50 years does not influence midterm results of heart transplantation. Transplant Proc 1996;28:91-2

20 Edwards BS. Symposium on cardiac transplantation: introduction. Mayo Clin Proc 1992:67:479.

21 Easterbrook PJ, Berlin JA, Gopalan R, et al. Publication bias in clinical research. Lancet 1991;337:867-72.
22 Reemtsma K, Gelijns AC, Sisk JE, et al. Supporting future surgical innovation. Lung transplantation as a case study. Ann Surg 1993; 218:465-73

23 Bavaria JE, Kotloff R, Palevsky $\mathrm{H}$, et al. Bilateral versus single lung transplantation for chronic obstructive pulmonary disease. J Thorac Cardiovasc Surg 1997; 113:520-7.

24 Griffith BP, Hardesty RL, Armitage JM, et al. A decade of lung transplantation. Ann Surg 1993;218:310-18.

25 Kriett JM, Kaye MP. The Registry of the International Society for Heart and Lung Transplantation: eighth official report - 1991. J Heart Lung Transplant 1991;10:491-8.

\section{IMAGES IN CARDIOLOGY}

\section{Large fistula between right coronary artery and right atrium in a 50 year old asymptomatic woman}

A

50 year old asymptomatic woman without prior medical history was found to have a continuous murmur, which was loudest in the lower right parasternal region. Her physical examination and standard ECG were normal. Transthoracic echocardiography revealed mild right ventricular dilatation, with trivial tricuspid regurgitation and transvalvar flow velocity estimated at $2.5 \mathrm{~m} / \mathrm{s}$. Left ventricular size and systolic function, and all valves, were normal. A hypoechogenic image was identified near the right ascending aortic wall, spherical at its origin, then extending linearly along the right, inferior margin of the right ventricle, without clear termination. Cardiac catheterisation (specially frontal and left lateral views of selective arteriography, performed with a 5 French Amplatz catheter) confirmed the presence of a huge, aneurysmal (measured to $9 \mathrm{~mm}$ at its origin), sinuous right coronary artery emptying widely into the right atrium just below the coronary sinus ostium, opacified retro- gradely over a few millimetres (black arrow). A small retroventricular arterial branch originated from the anomalous coronary artery (white arrow). Left ventriculography and left coronary angiograms were normal. Right heart and pulmonary artery pressures were normal, though pulmonary output was increased to 7.4 litres/min, with a calculated 1.48:1.0 left-to-right shunt. Exercise stress sestamibi scintigraphy showed normal myocardial perfusion.

This asymptomatic patient was recommended to undergo long term medical surveillance.

D Boulmier

M Bedossa

C Almange

$\mathrm{H}$ Le Breton

dominique.boulmier@chu-rennes.fr

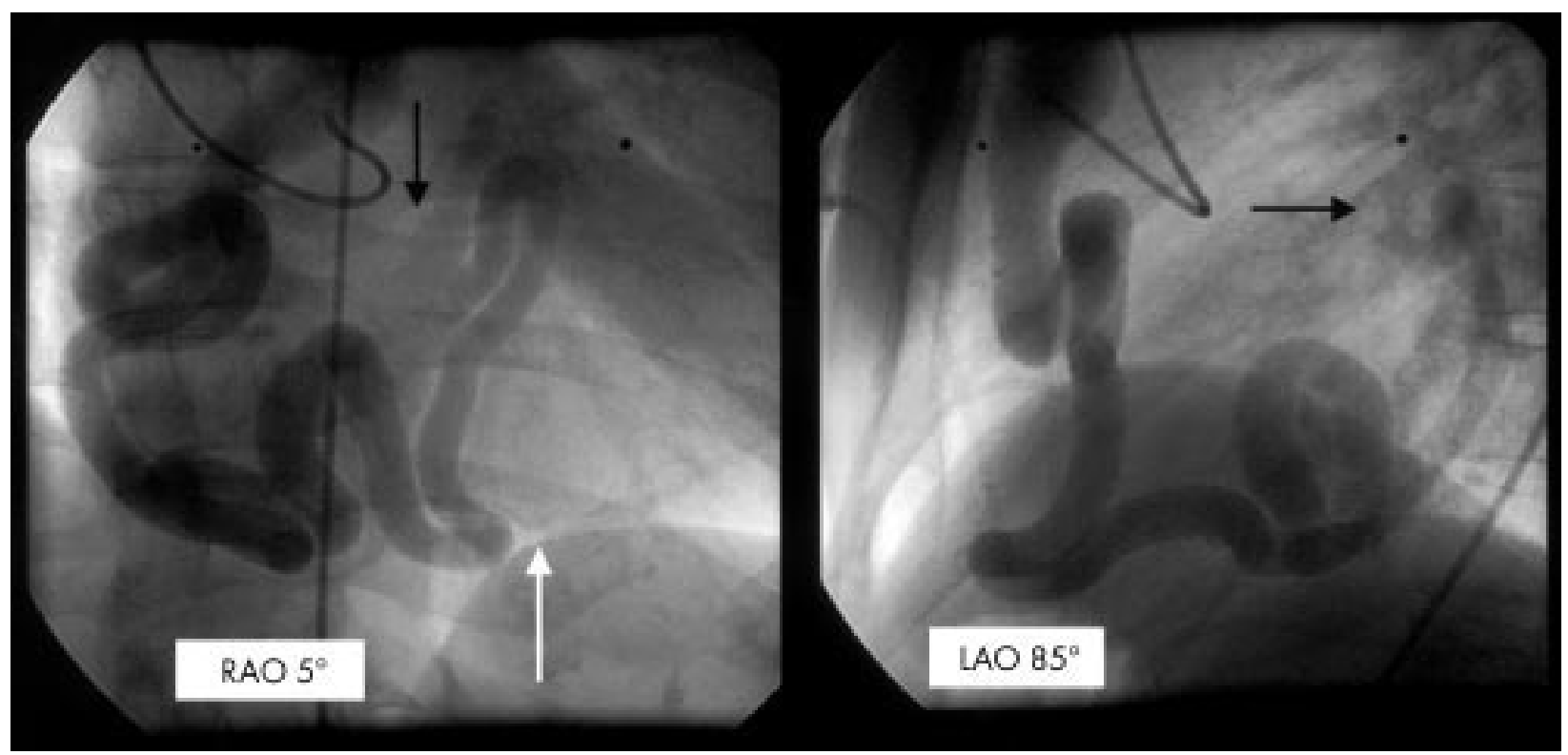

